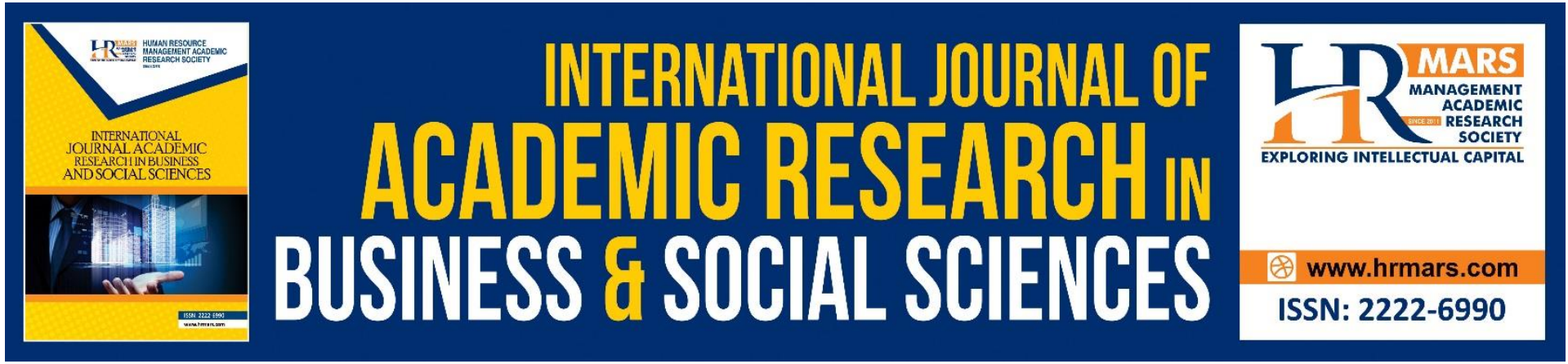

\title{
Logistic Role for Fine Art Sustainable Creative Industry
}

Rafeah Legino, Shareefa Al-Maqtari, Jalaini Abu Hassan, Shahriman Zainal Abidin

To Link this Article: http://dx.doi.org/10.6007/IJARBSS/v11-i9/11035

DOI:10.6007/IJARBSS/v11-i9/11035

Received: 08 July 2021, Revised: 26 July 2021, Accepted: 22 August 2021

Published Online: 05 September 2021

In-Text Citation: (Legino et al., 2021)

To Cite this Article: Legino, R., Al-Maqtari, S., Hassan, J. A., \& Abidin, S. Z. (2021). Logistic Role for Fine Art Sustainable Creative Industry. International Journal of Academic Research in Business and Social Sciences, 11(9), 515-521.

Copyright: @ 2021 The Author(s)

Published by Human Resource Management Academic Research Society (www.hrmars.com)

This article is published under the Creative Commons Attribution (CC BY 4.0) license. Anyone may reproduce, distribute, translate and create derivative works of this article (for both commercial and non-commercial purposes), subject to full attribution to the original publication and authors. The full terms of this license may be seen

at: http://creativecommons.org/licences/by/4.0/legalcode

Vol. 11, No. 9, 2021, Pg. 515 - 521

http://hrmars.com/index.php/pages/detail/IJARBSS

JOURNAL HOMEPAGE

Full Terms \& Conditions of access and use can be found at http://hrmars.com/index.php/pages/detail/publication-ethics 


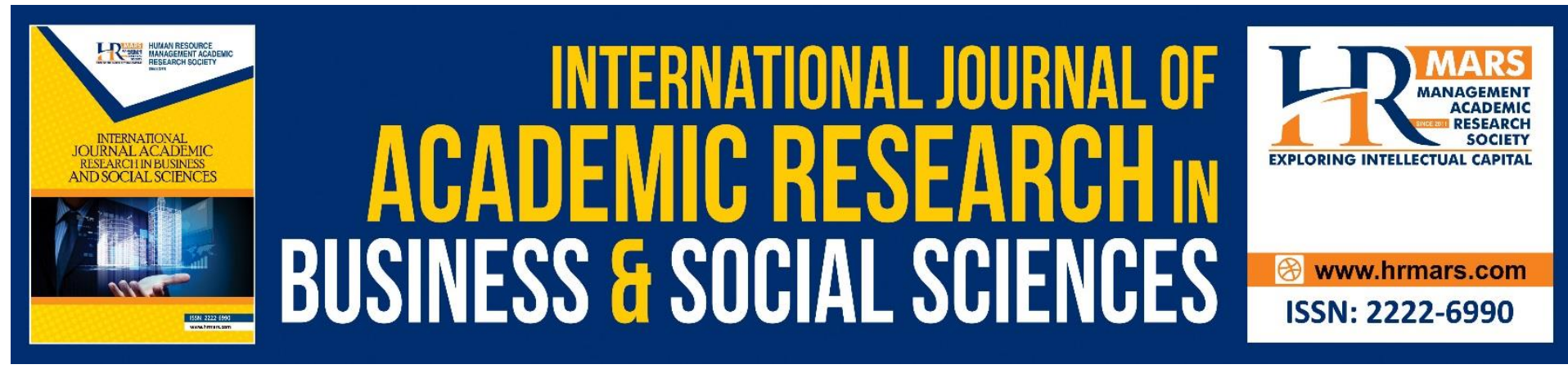

\title{
Logistic Role for Fine Art Sustainable Creative Industry
}

\author{
${ }^{1}$ Rafeah Legino, ${ }^{2}$ Shareefa Al-Maqtari, ${ }^{3}$ Jalaini Abu Hassan \\ 'Shahriman Zainal Abidin \\ ${ }^{1}$ Formgiving Research Group, Faculty of Art \& Design, Universiti Teknologi MARA 40450 \\ Shah Alam Selangor Malaysia, ${ }^{2}$ Faculty of Fine Arts, Hodeidah Uni. Rd, Al Hudaydah, Yemen \\ ${ }^{3}$ Department of Fine Art, Faculty of Art \& Design, Universiti Teknologi MARA 40450 Shah \\ Alam Selangor Malaysia \\ Email: rafeahl@uitm.edu.my
}

\begin{abstract}
The purpose of this study was to examine how the emergence of fine art logistics studies was primarily driven by the need for collaborative-innovative spaces to enhance the activities of the creative industry. Fine art logistics services are a relatively new branch of existing logistics resources in Malaysia. Third-party logistics providers' fine art logistics services and niche market strategy are both lacking and poorly researched. Indeed, cooperation between creative students at local universities, third-party logistics services, and niche market strategy in Malaysia. An effective fine art logistics digital platform based on the other study's successful model will improve and settle new innovative business trends, opening new opportunities for fine art graduate students in Malaysia's creative industry.
\end{abstract}

Keywords: Creative Industry, Fine Art, Logistic, Sustainable

\section{Introduction}

This study aimed to investigate how the emergence of fine art logistics studies was primarily driven by the need for collaborative-innovative spaces to enhance the creative industry's activities. Therefore, a fine art logistics digital platform by investigating the relations between creative students in any public university in this country, innovative third-party logistics services, and niche market strategy in Malaysia. The literary structure of this study will review the subjects of innovation production, niche market, innovation perspective in logistics, and logistics service capabilities. First, the theoretical framework will investigate innovation management concepts, four types of innovations, and dimensions by Bessant and Tidd (2007). Innovative logistics services and niche markets have been researched independently to contribute to strengthening creative industry activities. However, the relationship between third-party logistics service providers who provide innovative logistics services and niche markets are not well researched.

Innovative practices, third party logistics services providers, and niche markets specify fine art logistics as a new logistics sector in the creative industry. However, fine art logistics, the main branch in the art economy, is underestimated in logistics literature. Malaysian fine 
art logistics services appear to have insufficient guidelines and lack shared connections (Wang, 2018). Furthermore, innovative logistics services concept is underestimated and existing resources, acquired knowledge are limited in logistics literature (Madan \& Araz, 2013). On the other hand, the discussion revolved around a thorough study enhanced closely by understanding innovation and innovation management in Goffin and Mitchell (2016). The logistics innovation model was developed by Grawe (2009). For the potential niche market in Malaysia, we need to learn from the other models where logistics capabilities are developed and map the conceptual framework of fine art logistics via the digital platform. Exploration of information from the appropriate models like Crown Fine Art Logistics provider firm and Henry Butcher art auction will structure the logistics capabilities classifications and services providers. Finally, the idea will create an effective digital platform to link the innovative hub with logistic service providers to the Malaysian market.

\section{Results and Discussion}

The result and discussion for this study are based on the review that reflects the logistic role of fine art logistics. At first, when Houé (2020) mentioned the current situation, the innovative third-party logistics services revealed an opportunity for the fine art logistics concept. The fine art logistics service providers have a more innovative platform, in order to establish new business trends. Collaboration is also an initiative, where the study in UK studio pottery stated about the cooperation in how the artists collaborate with others in their production activities, and how this collaboration affects sales success (Jackson \& Tomlinson, 2009). On the other hand, in Taiwan, fine art logistics is deals with cross-disciplinary innovations. Taiwanese SMEs use technology to engage in global supply chains to adapt to the Fourth Industrial Revolution (Chen, 2020). The role of restored historic urban waterfronts as potential creative environments attracting creative visitors. Redevelopment of the waterfront poses challenges from a variety of urban planning and management perspectives, including space design and economical, environmental, cultural, and tourism considerations (Kostopoulou, 2013).

The other model in exploiting the economic potential in the handicraft industry in South Africa might be a source of income and employment for regular individuals living in rural regions. The promise of handcraft small businesses to provide sustainable livelihoods and reduce poverty has yet to be completely realised. The study revealed that two criteria significantly impacted the viability of handicraft businesses (Abisuga-Oyekunle \& Muchie, 2021). Small and medium-sized enterprises (SMEs) have a challenging time growing. The study adopts a contingency approach and adds to the literature on company strategy in fragmented sectors and SMEs' growth. There are also recommendations for practitioners and policymakers (Depperu et al., 2021). The fast growth of the global cultural and creative industries has ushered in a new era for Chinese traditional culture's development and creativity. The primary study points are traditional graphic patterns and local cultural meanings of the experimental region. It is believed that by digging deeper into historical patterns, the local economy, culture, and tourism growth may be accelerated (Li \& Lin, 2021). The Luxembourg Freeport is a free zone dedicated to storing, handling, and exchanging valuable artwork and jewellery. The findings show that these efforts extend beyond logistical and operational concerns. The results show a trifecta of resources that support this location in a virtuous loop of art, money, and logistics (Weeks, 2020). Low-income, inexperienced artists frequently struggle to make a living from their work. Their careers are in jeopardy because they cannot find studio space, have a sufficient budget for supplies, and do not have the time to focus on their work. Four painters were studied in this research, and while they 
all had various qualities, they all have a few things in common. Their coping techniques, material, and time constraints were not one-off fixes but were actively absorbed or integrated directly into their continuous creative process (Park, 2020).

The study looks at the role of stakeholders in the tourist and hospitality industries to secure their long-term viability. Stakeholder-based and resource-based theories were used to research Accra, Ghana's capital city (RBT), Due to their hectic schedules. The researchers had difficulty obtaining responses from specialists and managers in the tourist sector (Amoako et al., 2021). New research from Australia looks at the nature of art as a product from a network viewpoint, considering the role of essential players in defining its essence. The findings back up the idea of an art product shaped by the linkages and interdependencies of art market participants. Artists may use the results of this study at various phases of their careers to build suitable strategies and methods for creating their creative goods (Wickham et al., 2020). The development of the gig economy has opened up a slew of options for those working in the creative industries in recent years. This essay advocates for a shift in pedagogical mentality from a skill-based approach to a more holistic strategy that incorporates leadership in four areas: creativity, sustainability, vision, and community. The essay proposes Creative Industry Leadership as a new paradigm for encouraging a collaborative and comprehensive framework in the creative industries (Walzer, 2020). This chapter examines the literature on the relevance of cooperation between higher education institutions (HEI) and the creative and cultural industries (CCl), focusing on the African and Ghanaian contexts. Due to their ability to produce revenue, wealth, and employment, CCls quickly become essential components of modern post-industrial economies. There is no national curriculum in Ghana's higher education institutions. HEls are free to develop their curricula for providing creative arts (Bello, 2020). Customer-centric ideas are central to the present and commonly accepted view of quality. Alternatively, sustainability and digitalisation necessitate a quality perspective that includes various stakeholders. This framework is based on the concept of quality-in-use, which provides a means to guide and improve practical Quality Management procedures (Martin et al., 2020).

Therefore, an investigation into the relationship between entrepreneurial orientation, innovation ability, and company performance in the creative industries is the subject of this article. A survey-based empirical analysis is used in this work, as well as empirical research. It implies that success in the creative sector necessitates a close alignment of its entrepreneurial management and creative skills (Parkman et al., 2012). The Milla Digital project seeks to study the notion of the creative city: the drivers and elements that influence creativity in cities and how they promote long-term urban regeneration and innovation. The case study illustrates the Milla digital initiative in Zaragoza (Spain), in which place identification and innovation are vital components (Sepe, 2009). The government subsidises Korean performing artists to assist their creative endeavours. The researchers investigated the characteristics of Korean artists who get such awards and their employment and personal happiness. It demonstrated that art might be considered an excellent public benefit and a shared asset in society. The study concluded that artist subsidies should be increased to improve artists' quality of life and the long-term viability of artistic endeavours (Park \& Kim, 2020). Many young artists abandon their careers because they cannot balance creating work, living, and earning money. This study looks at how artists maintain their art practice in real-life settings by devising tailored solutions to their specific circumstances. Many struggling artists who have yet to find their means of maintaining their profession will benefit from it. The findings may be helpful to college art professors and school officials to prepare a curriculum to suit the practical 
demands of students who aspire to be artists as a career (Park, 2020). During the COVID-19 pandemic, these research study advocates enhancing supply chain management (SCM) performance in the culinary sub-sector of the creative economy development industry. It will be the subject of this study's challenge to investigate the impact of supply and distribution control on corporate performance. It indicates that particular economic sector efforts in the culinary subsector, notably in supply chain management, are required to deal with the COVID9 pandemic (Ubaidillah \& Riyanto, 2020). Creative Leadership (CL) is a tripartite leadership model developed and pioneered by Rama Gheerawo, the Helen Hamlyn Centre for Design at London's Royal College of Art. It evolved over the last decade through observation and experience of the limitations of hierarchical leadership models across a range of sectors. The following research stage and development involves a multidisciplinary convergence of design thinking with neuroscience-related brain plasticity, neural connectivity, and emotional intelligence theory (Gheerawo et al., 2020). The study looks at the impact of the Covid-19 crisis on the creative economy to generate ideas that will help the creative class find new ways to exist. Following a brief description and dimensioning of the creative economy, Section 3 demonstrates how various actors in the creative economy are dealing with the hygiene crisis. As a matter of survival, the dematerialization of innovative businesses/services is advocated. However, because artificially intelligent agents have previously been used as a separate "creative class," the same technology that may help may also be harmful. As a result, the necessary solution introduces new automated competitors (Nobre, 2020).

The research model was developed for managing creative sector innovation. And of course, the primary benefit of the study is a three-stage model for driving innovation in the creative industries. The idea, through a stage-based approach, can help creative sector practitioners looking to grow their businesses (Azis et al., 2017). For risk-averse students, deciding to study fine art can be challenging, especially in poor economic times with uncertain job prospects. Many artists supplement their income with side jobs, many of which are unrelated to the artistic field. Due to a lack of residencies, young artists sometimes struggle for at least three years following graduation. Artists are assumed to have a "calling" to live as artists rather than a "career," with no distinction made between "working" and "living" (Lee et al., 2018). Through an examination of changes in how Singapore Freeport is represented over the last ten years, the theoretical discourse in 2014 surrounding the Singapore Freeport as a one-stop-shop for art services that could theoretically contribute to the growth of the Southeast Asian art market as a result of the associative effects of the Bouvier Affair. The research demonstrates the significance of narrative economics and cultural policy in the development of art infrastructures such as the Singapore Freeport and its links to the Southeast Asian art market (Ditzig \& Lynch 2020).

\section{Conclusion}

To sum up, fine art logistics is an entirely new area of current logistics, and the acquired expertise is not well-known in Malaysia at this time. Research and quality are scarce on the relationships between Malaysian creativity, logistics service providers, and specialised market strategies. This project aims to develop a digital platform for fine art logistics by investigating the relationships that exist between creative students at our local institutions and innovative logistics services provided by third parties and specialised market segments. This research will provide a versatile and efficient digital logistic platform for fine art to enhance and address new business trends based on the successful model developed in the other study. 


\section{Acknowledgements}

The authors acknowledge this artistic research publication was support under the UiTM grant 600-IRMI/DANA 5/3/BESTARI (124/2018).

\section{References}

Abisuga-Oyekunle, O. A., \& Muchie, M. (2021). Handicraft small enterprises as an instrument for rural economic growth and poverty eradication. Problems and Perspectives in Management, 18(4), 25.

Azis, Y., Darun, M. R., Kartini, D., Bernik, M., \& Harsanto, B. (2017). A model of managing innovation of SMEs in Indonesian creative industries. International Journal of Business and Society, 18(S2), 391-408.

Amoako, G. K., Obuobisa-Darko, T., \& Marfo, S. O. (2021). Stakeholder role in tourism sustainability: the case of Kwame Nkrumah Mausoleum and centre for art and culture in Ghana. International Hospitality Review.

Bello, M. (2020). Collaborations for creative arts higher education delivery in Ghana: A case of the University of Cape Coast. In Higher Education and Policy for Creative Economies in Africa (pp. 28-43). Routledge.

Bessant, J., \& Tidd, J. (2007). Innovation and entrepreneurship. John Wiley \& Sons.

Depperu, D., Magnani, G., Crosato, L., \& Liberati, C. (2021). Growth of Firms in a Fragmented Cultural Industry: Italian Commercial Art Galleries' Competitive Strategies. Sustainability, 13(9), 5057.

Ditzig, K., \& Lynch, R. (2020). Art On/Offshore: The Singapore Freeport and Narrative Economics that Frame the Southeast Asian Art Market. Southeast of Now: Directions in Contemporary and Modern Art in Asia, 4(2), 161-201.

Gheerawo, R., Flory, M., \& Ivanova, N. (2020). Creative leadership: design meets neuroscience to transform leadership. Design Management Journal, 15(1), 102-117.

Grawe, S. J. (2009). Logistics innovation: a literature-based conceptual framework. The International Journal of Logistics Management.

Goffin, K., \& Mitchell, R. (2016). Innovation management: effective strategy and implementation. Macmillan International Higher Education.

Schreiber, R., \& Bota Moisin, M. (2021). Rebranding "Made in India" through Cultural Sustainability: Exploring and Expanding Indian Perspectives.

Houé, T. (2020). Art, Finance and Logistics: Creative Combination for Economic Development. Logistics and Transport= Logistyka i Transport, (45), 5-18.

Jackson, l., \& Tomlinson, P. R. (2009). The role of cooperation in a creative industry: The case of UK studio pottery. International Review of Applied Economics, 23(6), 691-708.

Kostopoulou, S. (2013). On the revitalised waterfront: Creative milieu for creative tourism. Sustainability, 5(11), 4578-4593.

Houé, T. (2020). Art, Finance and Logistics: Creative Combination for Economic Development. Logistics and Transport= Logistyka i Transport, (45), 5-18.

Lee, B., Fraser, I., \& Fillis, I. (2018). Creative futures for new contemporary artists: Opportunities and barriers. International Journal of Arts Management, 20(2), 9-19.

Li, X., \& Lin, B. (2021). The Development and Design of Artificial Intelligence in Cultural and Creative Products. Mathematical Problems in Engineering, 2021.

Madan, A., \& Araz, K. E. (2013). Fine Art Logistics: How Innovation Creates Niche Market for Third-Party Logistics Service Providers. 
Martin, J., Elg, M., \& Gremyr, I. (2020). The Many Meanings of Quality: Towards a Definition in Support of Sustainable Operations. Total Quality Management \& Business Excellence, 1-14.

Nobre, G. (2020). Creative Economy and Covid-19, Technology, Automation and the New Economy.Pobranez:http://www.researchgate.net/profile/Guilherme_Nobre/publicati on/340438912_Creative_Economy_and_Covid19_technology_automation_and_the_n ew_economy/links/5e8a71f4299bf130797ffc1e/Creative-Economy-and-Covid-19technology-automation-and-the-new-economy. pdf (2020.08. 01).

Park, K. T. (2020). Logistics of Space, Material, and Time: Struggles and Strategies for Sustaining Art Practice. Teachers College, Columbia University.

Park, H. S., \& Kim, H. C. (2020). Impact of Government Support on Performing Artists' Job and Life Satisfaction: Findings from The National Survey in Korea. International Journal of Environmental Research and Public Health, 17(20), 7545.

Parkman, I. D., Holloway, S. S., \& Sebastiao, H. (2012). Creative industries: Aligning entrepreneurial orientation and innovation capacity. Journal of research in marketing and entrepreneurship.

Sepe, M. (2009). Creative urban regeneration between innovation, identity and sustainability. International Journal of Sustainable Development, 12(2-4), 144-159.

Ubaidillah, R., \& Riyanto, S. (2020). The influence of supply chain management on the creative economy performance of the culinary sub-sector during the COVID-19 pandemic. International Journal of Innovative Science and Research Technology, 5(6), 10-16.

Wang, M. (2018). Impacts of supply chain uncertainty and risk on the logistics performance. Asia Pacific Journal of Marketing and Logistics.

Weeks, S. (2020). A freeport comes to Luxembourg, or, why those wishing to hide assets purchase fine art. In Arts (Vol. 9, No. 3, p. 87). Multidisciplinary Digital Publishing Institute.

Wickham, M., Lehman, K., \& Fillis, I. (2020). Defining the art product: a network perspective. Arts and the Market.

Walzer, D. (2020). Leadership in the creative industries: addressing an uncertain future. J. Music Entertain. Educ. Assoc, 20, 147-172. 